Article

\title{
Energy Potential Mapping: Visualising Energy Characteristics for the Exergetic Optimisation of the Built Environment
}

\author{
Siebe Broersma *, Michiel Fremouw and Andy van den Dobbelsteen \\ Department of Architectural Engineering + Technology, Faculty of Architecture, Delft University of \\ Technology, Julianalaan 134, Delft, The Netherlands; E-Mails: m.a.fremouw@tudelft.nl (M.F.); \\ a.a.j.f.vandendobbelsteen@tudelft.nl (A.v.d.D.) \\ * Author to whom correspondence should be addressed; E-Mail: s.broersma@tudelft.nl.
}

Received: 22 October 2012; in revised form: 23 January 2013 / Accepted: 24 January 2013 /

Published: 28 January 2013

\begin{abstract}
It is difficult to fully satisfy the energy demand of today's society with renewables. Nevertheless, most of the energy we use is lost as non-functional waste energy, whereas a large part of the built environment's energy demand is only for low-quality energy, so the initial demand for primary, high-quality energy can be reduced by more effective usage, such as by low-exergy means. Gaining insight into the parameters of energy demands and local renewable and residual energy potentials enables matching energy demand with a fitting potential, not only concerning quantity but taking into account location, temporality and quality as well. The method of Energy Potential Mapping (EPM) aims to visualise the energy potentials and demands by making information of quantity, quality and location of demand and supply accessible. The aspect of quality specifically applies to heat and cold. The methodology of EPM will be described and explained with case studies. The focus specifically lies on mapping heat (and cold), one of the main reasons for energy demand in the built environment. The visualisation of exergy, to be simplified as the quality of energy, becomes an extra parameter in the case of Dutch Heat Maps. These maps can help finding opportunities of practical implementations of exchanging or cascading heat or cold. This way EPM and Heat Mapping (HM) enables application of exergy principles in the built environment. EPM and HM can be seen as a local energy catalogue and can be useful in spatial planning for energy-based urban and rural plans.
\end{abstract}

Keywords: system dynamics; sustainable development; waste reduction policies; heat maps; energy potential mapping; EPM; heat cascading; heat exchange; built environment 
PACS Codes: 88.05.-b; 88.05.Sv; 88.05.Lg; 88.05.De

\section{Introduction}

The Energy Potential Mapping (EPM) method has evolved over the years and was initially developed to visualise local (renewable) energy potentials and demand of energy, in order to support spatial planning towards more energy-efficient urban or rural environments [1,2,3]. EPM has led to a process whereby energy becomes an extra parameter of spatial planning during the design of sustainable built environments. So far, fossil fuel, with a high energy density, extracted from the underground, produced centrally, and easily transportable, has been sufficiently available. Historically, the distribution of energy has hardly interfered with spatial planning. In a sustainable energy system, however, most sources need to be accessed at the Earth's surface, have a low energy density, are available in a very distributed way and are harder to transport. This means that in a sustainable world based on renewables, space equals energy, and sources and sinks must be spatially connected in smart ways. The EPM method is a means to map and quantify renewable energy potentials (e.g. solar, wind, geothermal, and biomass) and demand in a comprehensive way.

\subsection{Motivation}

The World's energy supply is currently dependent on fossil fuels, which, due to the exergetic mismatch between primary source and final use (requiring conversions), result in an estimated total global efficiency of $11 \%$ [4], thus generating a vast amount of entropy. Fulfilling a nation's energy demand with better suited local and regional renewables is certainly possible, but involves the smart use of local energy potentials, as MacKay demonstrated in the United Kingdom [5]. Even though some uses (transport and heavy industry) will continue to require high-density energy carriers, residential, commercial and public buildings (accounting for $35 \%$ of the total global final energy consumption) need a significant amount of low- and medium-quality energy (heating and cooling, hot water and cooking). This demand is currently particularly satisfied by the aforementioned high-quality energy forms of petroleum products and natural gas [6], presenting an exergetic challenge. In the case of heat and cold, the exergy factor of different energy users or functions is measured as the relative temperature [7]. The enlarged section in Figure 1 highlights the relatively small exergetic range that the built environment primarily operates in.

The prevailing practice of using fossil fuels to satisfy this demand not only leads to significant entropy generation, but also brings with it issues of longevity (being a finite resource), energy poverty [8] and energy security (defined as provision of reasonably priced, reliable and environmentally friendly energy [8]) as well as effects on global climate (more than half of global anthropogenic greenhouse gas emissions being attributable to fossil fuel use [9]).

Renewable energy sources however tend to be widely available to fill this gap, and can be harvested at various exergetic values, in different quantities and on different locations. Matching energetic qualities of supply and demand will significantly reduce entropy generation of the system as a whole. 
The same applies to residual flows from industrial and commercial sources, significant contributors to global entropy generation [4]. Utilising these flows by cascading heat reduces both the primary energy demand and thus the entropy generation for the full chain [10].

Figure 1. The exergy factor as a function of the system temperature divided by the reference temperature [11].

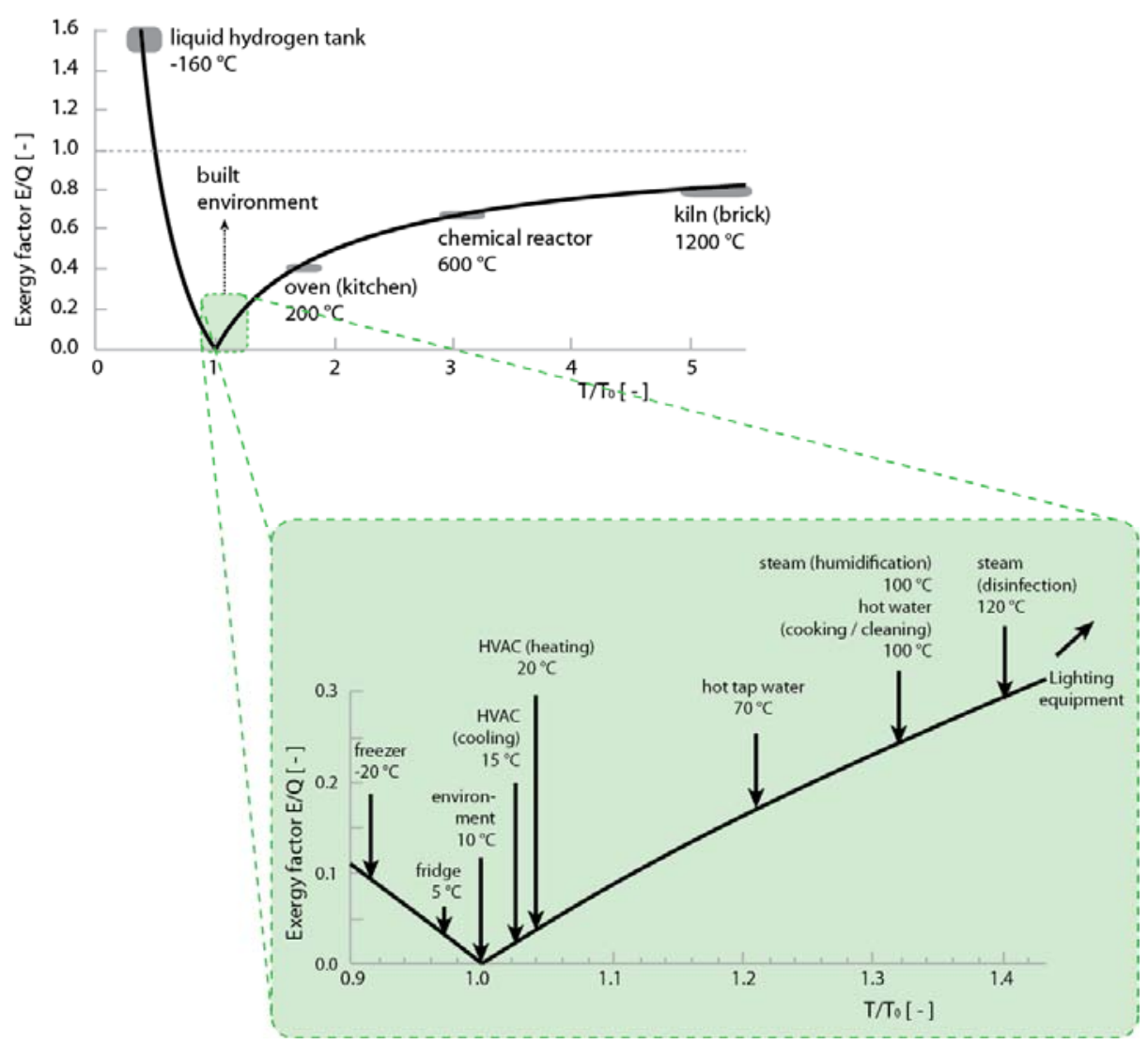

However, as transporting low-exergetic energy carriers over longer distances may result in significant dissipation into the environment (especially in the case of thermal energy [12,13]), thus increasing entropy generation, the geographic distance between source and sink becomes important.

Within the disciplines of architecture, urban planning and landscape design, second-law thinking (Stremke et al. [14], referring to Sciubba and Wall [15]), emphasises the importance of knowledge of the geographical, the temporal and the qualitative component of energy, next to the more familiar quantitative component, in using renewable and residual energy sources. This particularly applies to lower-exergetic energy, as this mainly exists in the form of heat, which is difficult and energetically expensive to transport over longer distances.

In order to design effective sustainable energy systems, it is important to have effective access to the aforementioned data, available not only to specialists in the various energy fields but also to policy makers, urban and regional planners, entrepreneurs and other parties. Facilitating accessibility of this information will enable implementation, and thus have a significant quantitative, worldwide impact on the qualitative mismatch between sources and sinks. That is the main aim of Energy Potential Mapping. 


\subsection{Energy Cascades and Low-ex Design}

Heat is one of the main forms of energy required by the built environment, and simultaneously the 'waste' of most energy conversion processes [4] (including in the built environment itself, in the form of low-temperature heat).

The heat required tends to be generated using high-quality primary energy sources for all end-users, from heavy industry to agriculture (Figure 2). This either results in a significant amount of entropy generation from these high-quality sources at the low end, or a significant amount of 'waste' heat released into the atmosphere and open water by high-temperature emitters, even though that heat can certainly be considered as a 'competitive by-product' (Valero et al. [16] referring to Nakamura and Kondo [17]).

Each of these users has specific temperature ranges as input and output, and as the heat exhaust of some waste streams matches the required temperature of others, it is possible to cascade heat at different temperatures between various functions, in order to significantly reduce entropy generation for the system as a whole (Figure 3).

Figure 2. Current energy system.

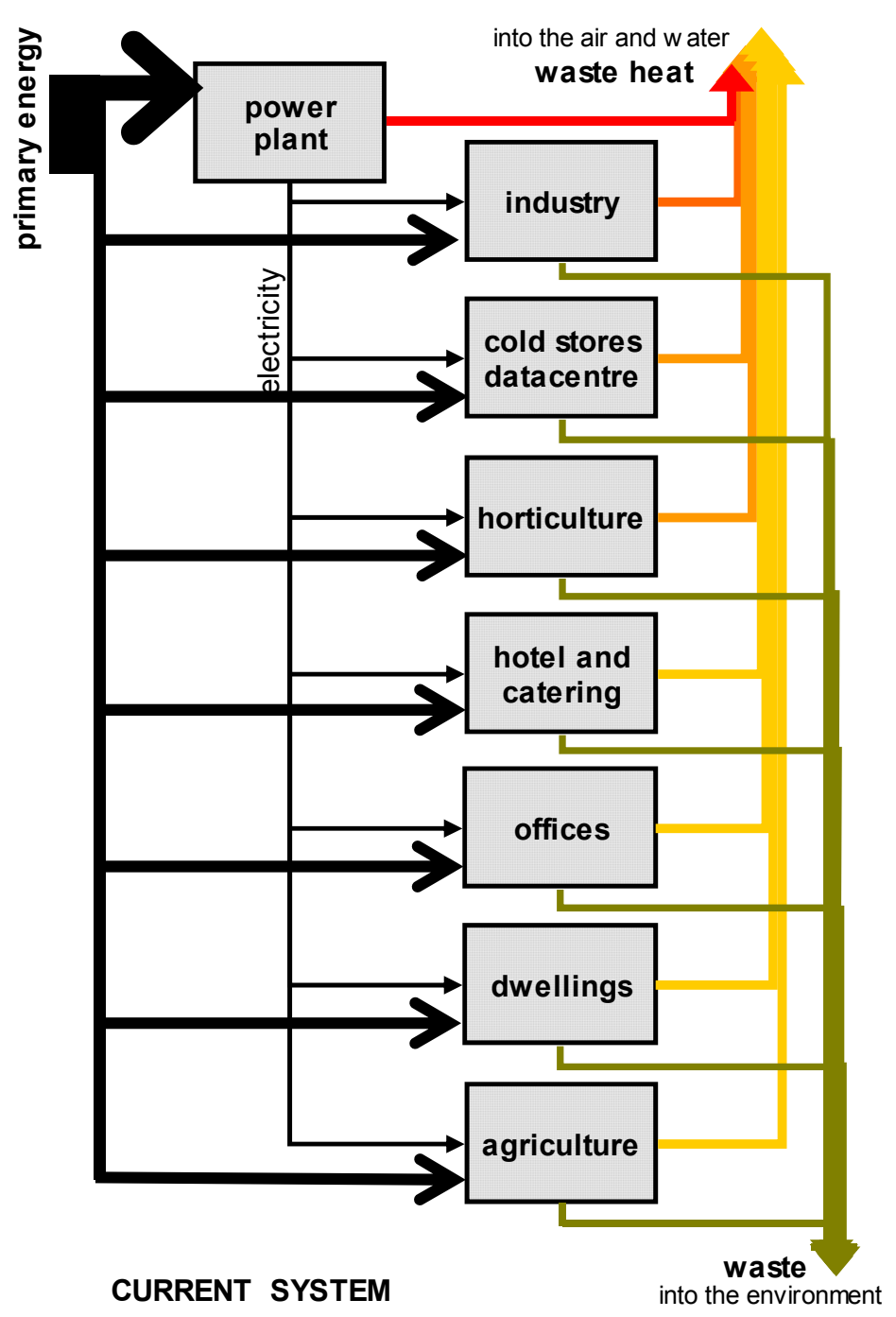


Figure 3. Cascaded energy system.

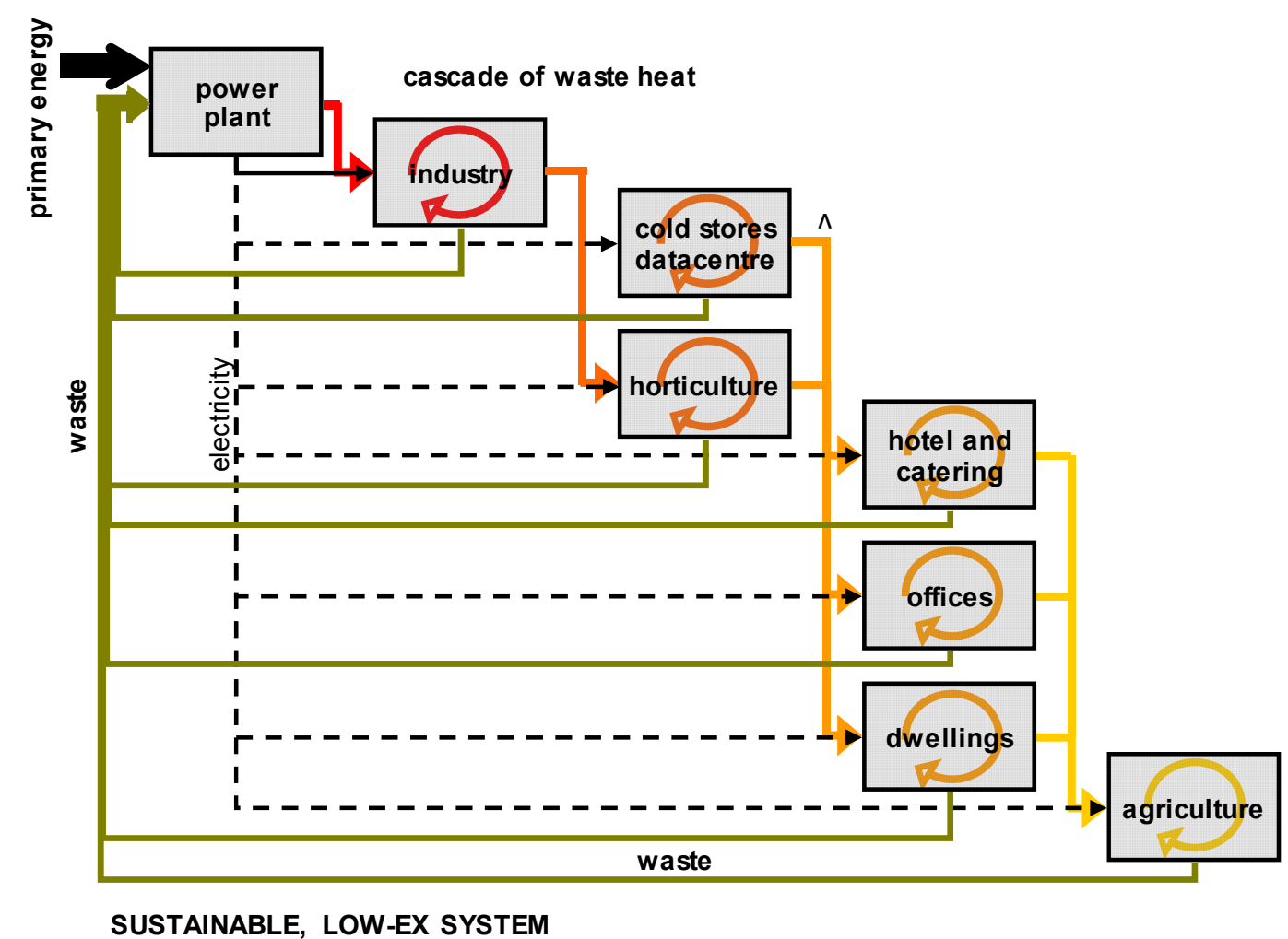

\subsection{Missing Knowledge}

Exploring the spatial aspects of renewable energy is not new. Individual renewable energy potentials for solar and wind power have been mapped before, however few studies have attempted to combine these potentials without sacrificing spatial data. Voivontas et al. developed an early GIS decision support system for Crete where potentials were determined using a set of sequential steps, from theoretical, available and technological to economically exploitable [18], and Ramachandra and Shruthi explored solar, wind, bio-energy and small hydro-energy potentials for Karntaka state, India [19]. Unique to EPM is that it spatially normalises energetic yield for the various energy potentials (e.g by $\mathrm{GJ} / \mathrm{ha}$ ), and formalises the separation of exergetic qualities in a manageable form by assessing demand and supply based on the energy carrier type they can require or produce. Hence EPM provides insight into the location-specific demands and potentials of heat and cold at different levels, electricity, fuels, and sometimes also the carbon sequestration potential, and through the method these energy features are represented in clear maps, either stacked, or combined, 2-D or 3-D. EPM thereby provides an energy catalogue that will both facilitate directly matching these qualities, and creating energy cascades.

\section{Methodology}

\subsection{General Method}

The purpose of an EPM study is to provide a comprehensive overview of the characteristics of energy sources, sinks and infrastructures within an area. Theoretically, all energy sources imaginable 
can be subject to an EPM study but generally renewable and anthropogenic (e.g. residual heat) sources are studied. The energy demand may originate from buildings or transportation; for buildings it can roughly be divided in heat and cold loads and electricity demand. Buildings can be subdivided into different functions e.g. dwellings, commercial and industrial buildings.

In order to gain a geographical imprint of an area's energy characteristics, firstly the output of data needs to be defined. This concerns the area itself and the regarded energy sources, sinks, storage and energy infrastructures. But as conversion losses will make it impossible to fully harvest a theoretical energy potential from a given source, the output must be defined by how the availability of different energy sources is classified. This will vary on a sliding scale from what is theoretically available to what is reasonably possible, e.g. using a common technique with a representative efficiency. The latter will give a reliable overview of the area regarded at that time, and it may often be favourable. Therefore, secondly for each source the applying limitations of the energy potentials need to be expressed. The following equation describes this process:

$$
\left[\mathrm{T} * \mathrm{~L}_{1} * \mathrm{~L}_{2} * \ldots * \mathrm{~L}_{\mathrm{n}}=\mathrm{E}\right]
$$

Within this equation, $\mathrm{T}$ represents the theoretical energy potential, which is solely limited by the laws of physics, $\mathrm{L}$ is a limiting factor and $\mathrm{E}$ is the annual defined energy potential. The main limiting factor will be of technical nature, being conversion techniques, while additional factors tend to be of social, political or economic nature.

Further to identifying the limitations, the desired characteristics of energy (quantitative, qualitative, temporal,...), and their units have to be defined, and finally the spatial yield of energy sources can be determined.

The next scheme (Figure 4) illustrates the methodology of EPM, starting on the left with redefining the current use into the actual energy demand of heat, cold, electricity and fuel. Simultaneously on the right, the theoretic potentials are defined out of the basic input for each source and into the available heat, cold, electricity and fuel after regarding the limitations. Sources and sinks meet in the middle, where they can be smartly connected in energy based plans.

After defining the desired output, available sources of literature and (monitored) data need to be studied to obtain the optimum available input on the quantities, qualities, and geographic and temporal dispersion of all defined sources and sinks. Data obtained at the smaller scale e.g. available residual heat of small scale industries and the biomass of individual farms, is often unavailable. In the absence of such primary data alternative methods need to be applied to calculate or estimate, alternatively the scale at which to express the output must be enlarged.

Since the availability of data may change over time, an EPM study gives an overview of the best available data at that moment. If at a later date more accurate data or real-time measurements become available, the catalogue of energy potentials can be updated.

Finally, the way of visualising the output needs to be decided. When multiple characteristics of sources or sinks have to be presented, visualisation techniques become more complex. Uniformity of data (encompassing one type of energy) offers the opportunity to present more information in one overview. There are various ways to visualise the output. The following sub-sections describe the visualisation of input and output, as well as ways to convert input into output. 
Figure 4. Scheme of the methodology of EPM.

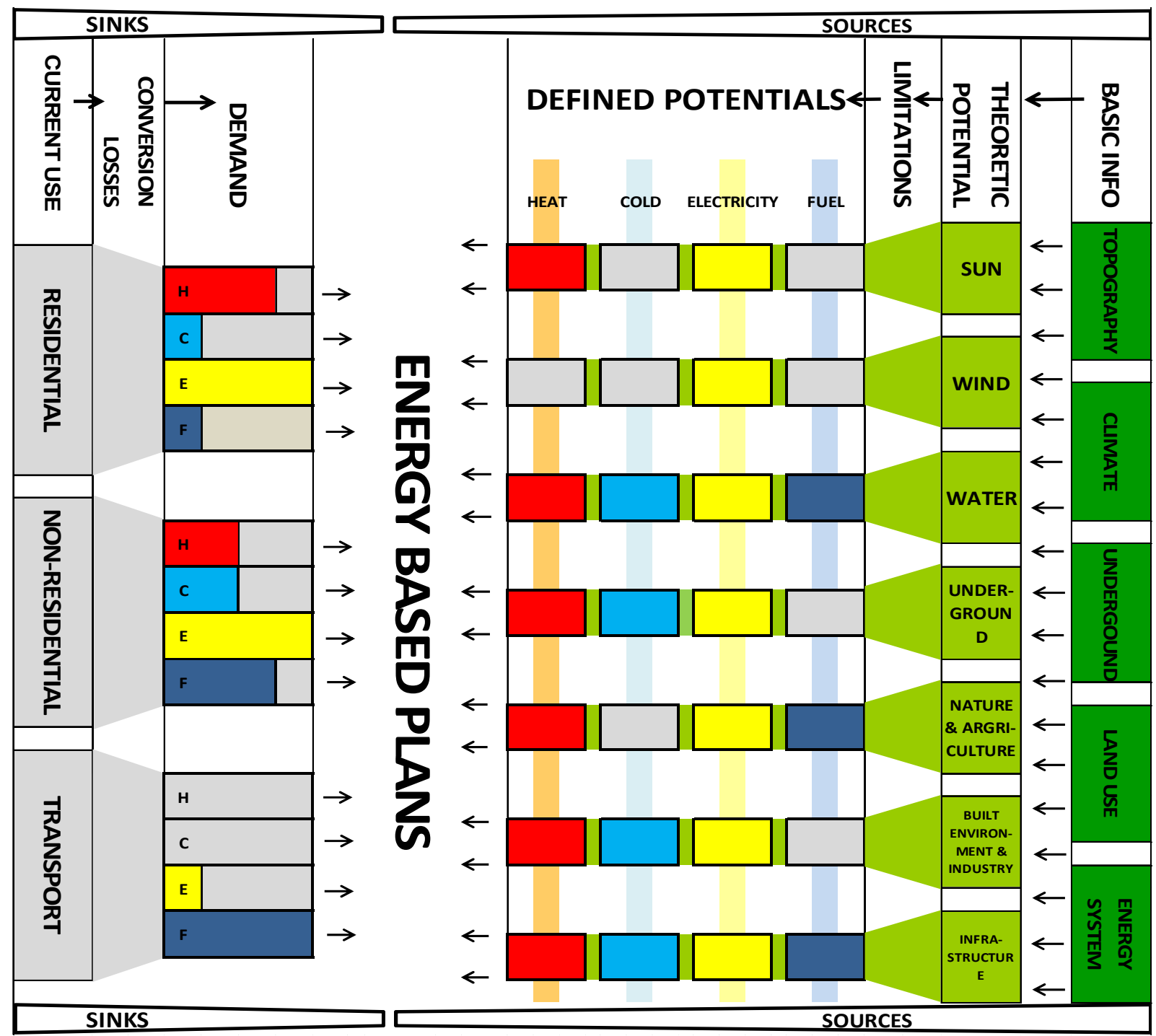

\subsubsection{Input}

Desired output: Before discussing the input, the desired output must be defined. Output will generally consist of one or more of all renewable and anthropogenic energy sources, energy demands, transport and storage possibilities of an area, expressed in a pre-defined way.

After defining the considered area, appropriate and equalised units are chosen to express the available sources and sinks. Depending on the scale of the study this may vary but GJ/ha or GJ are commonly used units for all sources and sinks.

A spreadsheet of all above-mentioned variables will contain the output. In all EPM studies the final output will depend on the availability of input data and may not always correspond to the output initially desired.

Sinks: The input data required to define the energy demand will mostly consist of energy use data. By then, the energy users have been defined, and can subsequently be divided in various groups that either have a precise location (e.g. a factory) or an area (e.g. a residential area). Road networks can be 
considered as elongated areas. These sinks may often depend on the availability of data, this in turn setting the scale, and therefore the resolution or division of the area in blocks or neighbourhoods.

Sources: Renewable energy originates from the sun, wind, water, soil, biomass, or the built environment. After the selection of sources to be involved in the EPM study, their theoretical potentials need to be ascertained.

In order to calculate theoretical potentials, one requires basic information on climate, topography, geography, land use, underground and built environment. In order to calculate the Sun's energy potential the annual solar radiation per square meter that reaches the Earth's surface is considered. For wind, the average annual wind speed is a common parameter. Water energy can be harvested in different ways; for hydro-electric energy, heights and annual quantities of water flow rates, or average river speed can serve as the required data inputs. In order to define the amount of heat available in geothermal sources, temperatures and volumes of existing underground aquifers are data inputs. For biomass, amounts of waste streams such as from inhabitants, livestock and data of land use must be determined. Anthropogenic sources, e.g. residual heat from industries, are not theoretical amounts but directly available.

Storage: Because some renewable resources may have a fluctuating delivery potential, energy storage systems are needed to make their energy available at times other than it was harvested or produced. As with the energy sources themselves, storage systems deal with geographical and quantitative (as well as qualitative and temporal) input that can be mapped.

Heat and cold storage systems have a specific theoretical capacity to store either heat and/or cold water. Water basins or salt caverns act as storage systems for potential energy to be converted into electricity. Input data being volume, height and pressure.

Energy infrastructures: Infrastructures have geographical and quantitative/qualitative characteristics e.g. heat or electricity networks.

\subsubsection{Energy Conversion Techniques}

In the EPM methodology, for each source or sink the technical limitations of present-day energy techniques, which convert an energy source into a useful form of energy, have to be determined.

The energy demand can be recalculated by multiplying the energy use by the average efficiency of the conversion techniques used. Domestic electricity use can be multiplied by the average efficiency of power plants to get insight into the actual electricity demand. For heat demand this can be done, for instance, by assuming gas use and the average efficiency of boilers.

In order to calculate potential yields of different energy techniques, their properties must be known, as well as formulas to convert theoretical potentials into realistic ones. To give but one example: the electricity that can be harvested from the sun is limited by the (average) efficiency of common solar cells. Modern mono- or poly-crystalline solar cells have an average efficiency of $15 \%$, while more expensive ones perform at 20\% [6]. Thermal energy can be harvested at higher efficiencies depending on the techniques used. Multiplying the annual solar radiation by the average efficiency is one way to determine the annual yield per unit of area. 


\subsubsection{Determining the Spatial Yield}

In order to determine the final yield of each energy source, financial, political, social or other technical limitations must be taken into account and quantified or allocated. For solar energy other limitations may be adopted, such as avoiding single land use. This decreases the area of available space to harvest solar energy. For wind or underground storage of energy, political limitations may occur in the form of restrictive areas. Other limitations with a technical background are for instance wind turbines, which have a certain minimum mutual distance where interference is still acceptable. For geothermal sources at a certain depth, the annual heat influx from the Earth's core can be seen as the real renewable amount to harvest, as opposed to all heat in place.

\subsubsection{Output}

The output will consist of a database with equivalent figures of energy demand and supply, which in each case are coupled to points, fields or lines on the map of the area under investigation.

\subsubsection{Visualisation}

The final step in EPM is presenting the data of all individual energy potentials through maps. The structure of these maps depends on the type of energy. Common methods apply a cell structure (cells being for example the neighbourhoods of a city) and display values with a colour scale, pinpointed locations of energy structures (demand or supply), display energy networks or indicate search ranges for certain technologies. Combining these in a map stack presents a so-called 'palette of possibilities' for the area, providing a quick overview of renewable energy potentials and allowing them to be offset against the energy demand (as well as the demand reduction potential). Several examples of EPM maps will be discussed in the following chapter.

\section{Case Studies}

\subsection{Heat Maps}

In the year 2010 the TU Delft executed a specific EPM study entitled 'Heat Mapping' that focused exclusively on heat and cold [20]. The objective was to visualise in a single overview all heat demands and potentials of an area, in comparable quantities. Both The Netherlands as a whole and some of its district regions were studied.

The desired input used for the heat maps is listed in Table 1, which indicates which characteristics of heat had to be defined for each type of demand, supply or infrastructure, being location, quantity and quality. Not all desired data was available during the secondary research phase (marked in dark grey), the variables finally quantified are marked in red. The two columns on the right indicate the groups of demand, supply and infrastructures that were found suitable for each scaled map, national $(\mathrm{NL}=$ the Netherlands) or regional. The temperature column finally indicates whether the specified item can be tied to a specific temperature or range, as this property may for example indicate cascading opportunities. 
For the various natural resources the potentials were determined as the annually available amount of heat that can be harvested in a sustainable way, using present-day techniques and avoiding single land use.

Table 1. Example of input values to be determined.

\begin{tabular}{|c|c|c|c|c|c|}
\hline \multicolumn{6}{|c|}{ Input: desired data and variables } \\
\hline \multicolumn{6}{|c|}{ demand } \\
\hline \multicolumn{6}{|l|}{ Bulk consumers } \\
\hline Industries & area & $\mathrm{GJ} / \mathrm{PJ} / \mathrm{ha}$ & 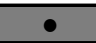 & & $\bullet$ \\
\hline Greenhouses & area & $\mathrm{Gj} / \mathrm{ha}$ & $\bullet$ & $\bullet$ & $\bullet$ \\
\hline Hospitals & point & $\mathrm{Gj}$ & $\bullet$ & $\bullet$ & $\bullet$ \\
\hline Swimming pools & point & $\mathrm{Gj}$ & 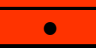 & & $\bullet$ \\
\hline \multicolumn{6}{|l|}{ large scale consumers } \\
\hline Residential area & area & Gj/ha & - & - & $\bullet$ \\
\hline Commercial buildings & area & $\mathrm{Gj} / \mathrm{ha}$ & $\bullet$ & & \\
\hline \multicolumn{6}{|c|}{ supply } \\
\hline \multicolumn{6}{|l|}{ Residual heat sources } \\
\hline Powerplant & point & $\mathrm{GJ} / \mathrm{PJ}$ & $\bullet$ & $\bullet$ & $\bullet$ \\
\hline Incinerator plant & point & GJ/PJ & $\bullet$ & $\bullet$ & $\bullet$ \\
\hline Supermarkets & point & G] & $\bullet$ & & $\bullet$ \\
\hline Specific heavy industries & point & GJ/PJ & $\bullet$ & & \\
\hline \multicolumn{6}{|l|}{ Biomass } \\
\hline Sewage treatment plant & point & $\mathrm{Gj}$ & $\bullet$ & $\bullet$ & $\bullet$ \\
\hline residual biomass & area & $\mathrm{Gj} / \mathrm{ha}$ & I & & \\
\hline \multicolumn{6}{|l|}{ Solar collectors } \\
\hline global radiation & area & $\mathrm{Gj} / \mathrm{ha}$ & 1 & $\bullet$ & \\
\hline " on roofs & area & $\mathrm{Gj} / \mathrm{ha}$ & $\bullet$ & & $\bullet$ \\
\hline " on roads & area & $\mathrm{Gj} / \mathrm{ha}$ & $\bullet$ & & $\bullet$ \\
\hline \multicolumn{6}{|l|}{ Geothermal } \\
\hline underground (0-50m depth) & area & suitability & 1 & $\bullet$ & $\bullet$ \\
\hline shallow (50-300m depth) & area & suitability & 1 & $\bullet$ & \\
\hline deep $(>2000 \mathrm{~m})$ & area & $\mathrm{Gj} / \mathrm{ha}$ & $\bullet$ & $\bullet$ & $\bullet$ \\
\hline \multicolumn{6}{|c|}{ infrastructure } \\
\hline district heating & layout & & 1 & $\bullet$ & $\bullet$ \\
\hline $\mathrm{CHP}$ & point & & l & & $\bullet$ \\
\hline Biomass installation (CHP/incinerator) & point & & 1 & $\bullet$ & $\bullet$ \\
\hline
\end{tabular}

The locations are expressed as points or (diffuse) areas expressed by GJ or GJ/ha per year or where no quantified data was available, by suitability in case of underground storage and underground heat exchange.

The data is divided into categories of demand, supply and infrastructures. For each of the regional and national maps the data was collected in comprehensive spread sheets detailing each sub-region. On completion the data was then visualised.

In heat maps the heat demand is depicted as a series of elevated contours; the heat supply potential present subsequently fills the resulting sink. Note that, although this can be compared to filling a bucket, height rather than volume indicates the amount of energy, as this makes it better possible to assess a collection of areas of different sizes. When all these individual 3-D maps are stacked, the resulting 3-D landscape quickly indicates where demand may potentially outstrip supply, and vice versa. Point sources, such as supermarkets, swimming pools, industries and power plants, are depicted by cylinders, where the colour denotes heating or cooling load and hollow cylinders represent the net demand for an installation. Larger roads can be equipped with integrated pipes to become giant solar 
collectors and are depicted as yellow bands. When present, a district heating grid providing heat transport opportunities is hatched in red.

Figure 5. Heat maps of The Netherlands (left) and Rotterdam (middle right).

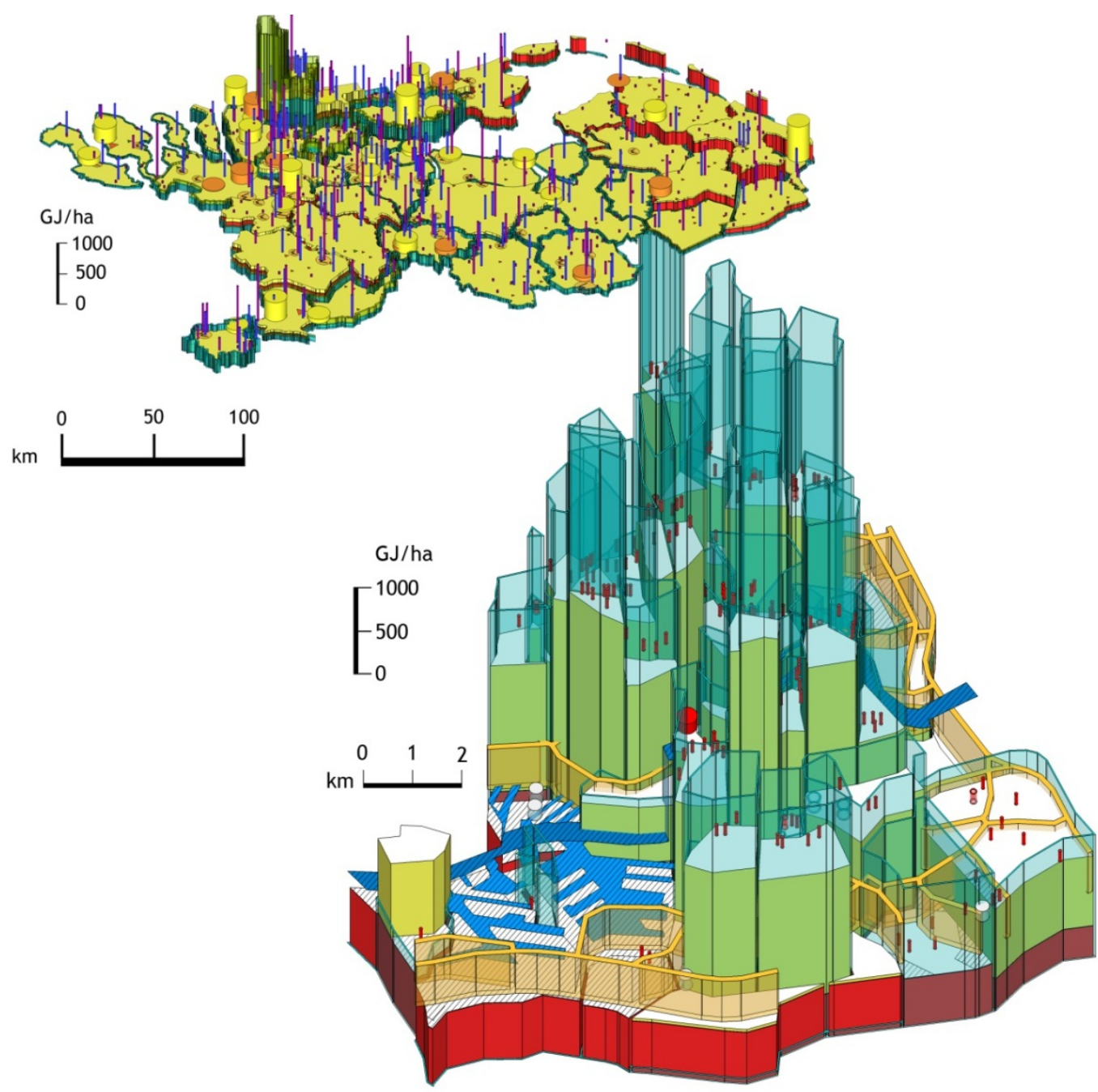

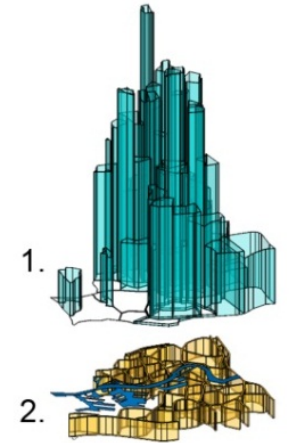
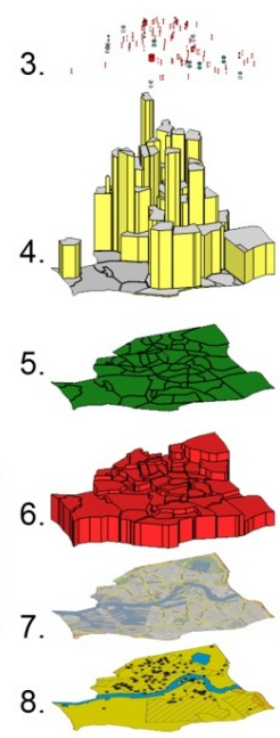

Figure 5 shows an example of a heat map of The Netherlands (upper left) and for the city of Rotterdam (middle; simple 3D modelling software was used for the graphs). The right graph shows the stacked annual supply potentials (and demand) of the middle graph, from 1 to 8 representing: 1) heat demand of dwellings, 2)heat potential from road collectors, 3) point sources and sinks of heat and cold (supermarkets, hospitals, power plants etc), 4) heat potential from roof collectors, 5) heat potential from biomass, 6) geothermal heat potential, 7) map of the area, 8) soil suitability for underground vertical heat exchangers. Although at the time insufficient data on industrial processes was available (as visible in the lower left harbour area), the map does show the discrepancy between the densely populated centre (demand) and much sparser populated periphery, a possible opportunity being diverting excess geothermal flux at the latter areas to the former by means of district heating. Also clearly visible is that the demand for heat in the city is generally twice as high as the potential to be yielded from the sun and geothermal sources, an insight supporting the idea that energy savings remain an important means to establish sustainability. 


\subsection{The Veenkoloniën}

In 2010 the northern Dutch provinces of Groningen and Drenthe commissioned the TU Delft to execute an EPM study and provide them with carbon-neutral energy visions and spatial plans for sustainable energy systems for the region of the Veenkoloniën [21]. The Veenkoloniën, literally meaning 'peat bog colonies' (the area being a former provider of peat, a historic heating fuel) is a relatively low-density and economically poor region area of $800 \mathrm{~km}^{2}$.

Figure 6. Energy potential maps of the Veenkoloniën.

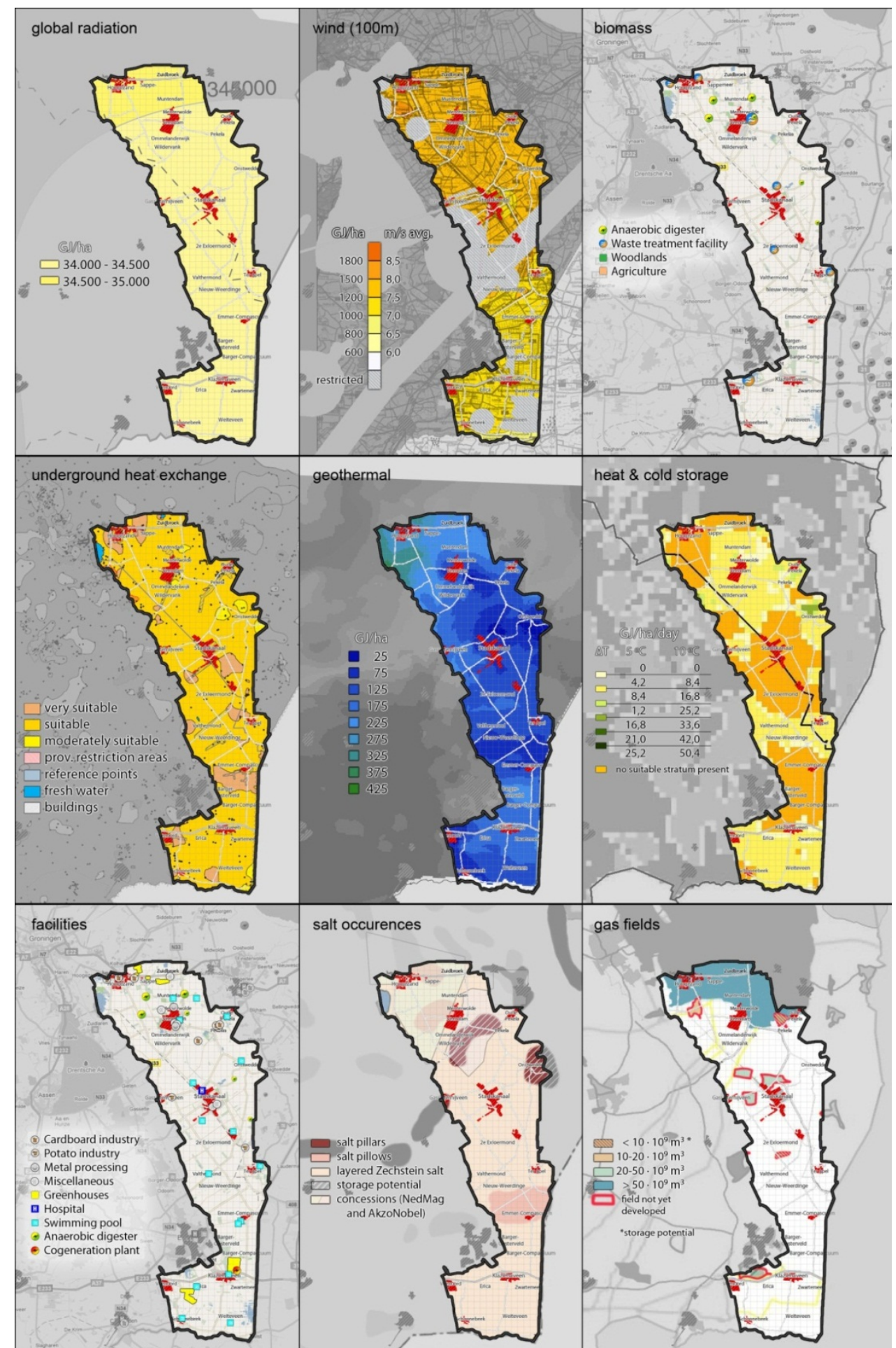


Figure 7. Energy vision map of the Dutch region of Veenkoloniën.

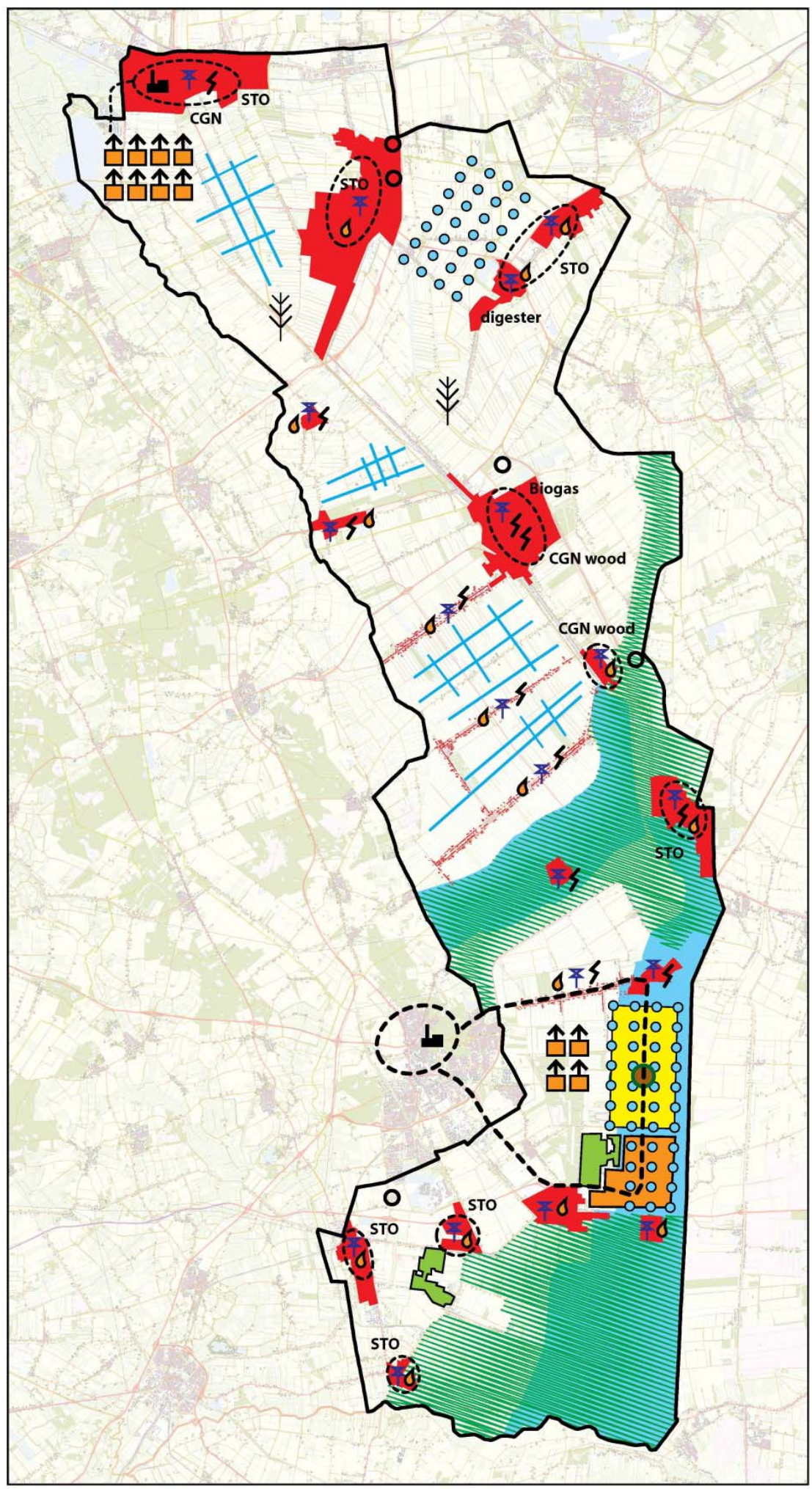

\section{Integrated energy vision}

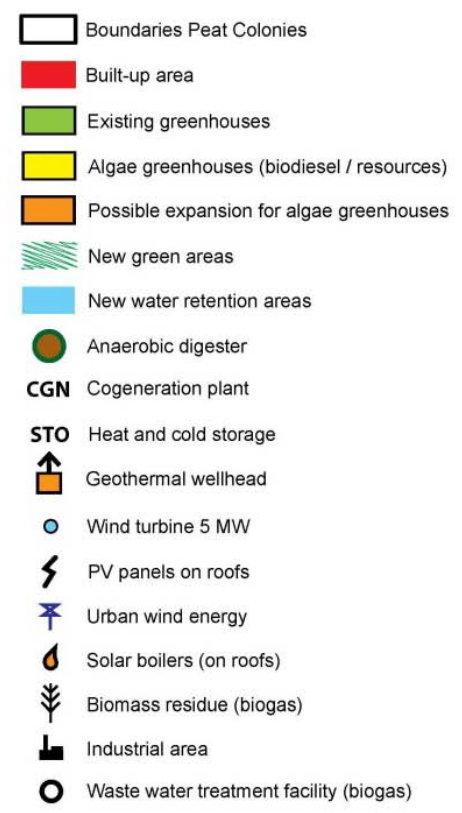

.... Local district heating
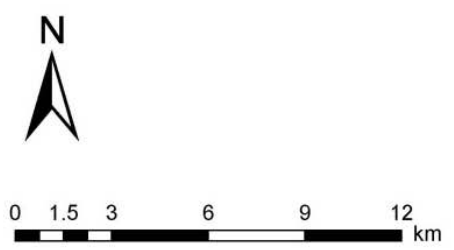

Authors:

Andy van den Dobbelsteen, Siebe Broersma, Michie Fremouw, Renée de Waal, Sven Stremke, Kasper Kl

A full EPM scan was executed for all renewable sources including different types of storage. The maps were accompanied with tables of yields from different energy techniques clarifying the realistic potentials for different cases in the Veenkoloniën (Figure 6). Next to mapping the available supply potentials, a reference calculation was made for the energy demand. Together they form the basic 
catalogue for the quantification and subsequent design for sustainable energy systems in the Veenkoloniën area. The energy demand was qualitatively subdivided into its original demands for heat, electricity, fuel for transport and industrial processes.

In a next step the demand was shifted in origin and reduced by measures that fitted the specific energy vision. These measures concerned assumptions in energy demand reductions by thermal insulation or low-energy vehicles. Shifting demands may result from assumptions of the share of electric mobility in a scenario or the share of electric heat pumps to fulfil heat demand.

Finally the remaining demand was met with a mix of energy sources, regarding availability, suitability and the context of a total energy system that fits the scenario. This was a process of finding different suitable energy concepts for different situations in the area, based on the local potentials and dimensioning these with the demand, until demand, supply and storage were quantitatively and qualitatively balanced.

The EPM for the Veenkoloniën resulted in two extreme yet sustainable energy visions. One turned the Veenkoloniën into an effective food, materials and exergy machine for the Netherlands by means of region wide cooperation ('Veenkometro', to be translated as Peatropolis); the other was a more modest solution, where each town or village realised its own energy-neutrality ('Alleenkoloniën', to be translated as 'Alonecolonies'). Figure 7 illustrates the proposed map for a mixed vision that incorporates elements of both these extremes.

\subsection{De Groene Compagnie}

De Groene Compagnie ('The Green Campaign') is a newly planned district located south of the town of Hoogezand in the Dutch province of Groningen. An EPM study was executed to contribute to the urban plan [22]. For De Groene Compagnie study, the stacked energy potential maps made the local potentials clear (Figure 8). Not only the theoretical potentials were visualised, but also the realistically harvestable amounts of energy, taking into account technical efficiencies.

\section{Discussion and Outlook}

Although EPM has been used in many studies by the authors, ranging from neighbourhoods and individual cities to regions and provinces, it has proven possible to formalise the process with a structured methodology. In the evolving process of EPM, TU Delft wants to work towards a generic model that integrates energy databases in order to calculate energy potentials for a specific location or area by means of a web tool. A proposal was recently submitted to build a quick scan tool, which would provide various stakeholders in the building process with instant information on the energy potentials of a location, for example by means of a GPS-enabled smart phone. Access to this type of information will instantly allow appropriate decision making early in the design process, when it has the most effect on a project's performance. This economic efficiency is its greatest influence, both in facilitating increased use of renewable energy, and reduced generation of entropy in the built environment. 
Figure 8. Energy Potential Pile of 'De Groene Compagnie'.

\section{Energy Potential Pile - 'De Groene Compagnie (DGC)'}

\section{Energy Potencials}

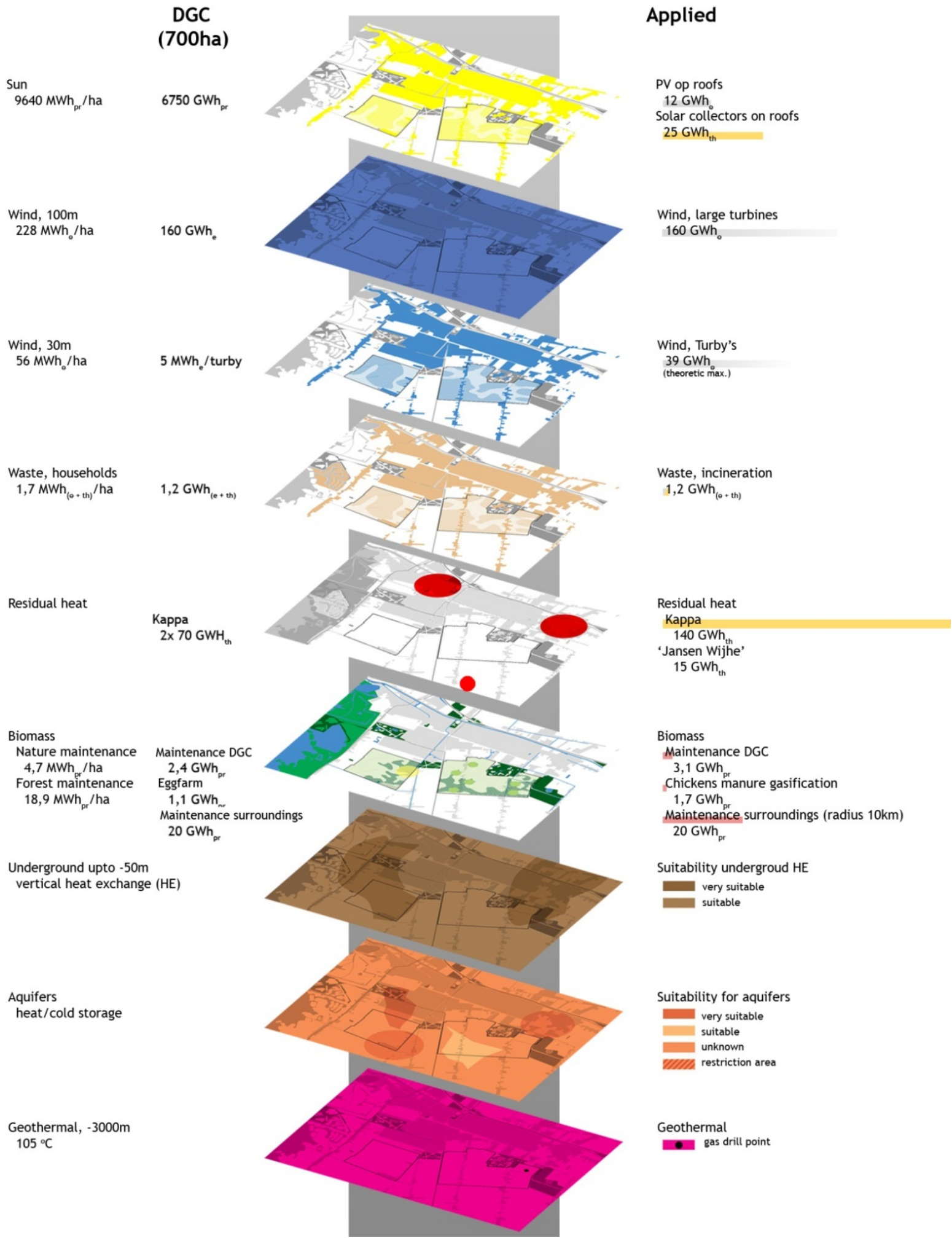

Energy demand 3000 households:

$10,6 \mathrm{GWh}$

$26,5 \mathrm{GWh}_{\text {th }}$

Applied

collectors on roof

$25 \mathrm{GW}$

Wind, large turbines

$160 \mathrm{GWh}$

Wind, Turby's

(theoretic max.

Waste, incineration

$1,2 \mathrm{GWh}_{(0+\mathrm{t}}$

Mintenance surroundings (radius $10 \mathrm{~km}$ )

$20 \mathrm{GWh}$

very suitable

tability for aquifers

very suitab

othermal

gas drill point 
Recently, the TU Delft organized a workshop for governmental employees working in the field of historic Dutch inner cities, to learn about the energy potentials in these specific urban situations. A follow-up research is expected to expose the limitations en chances of energy potentials in historic inner cities.

\section{References and Notes}

1. van den Dobbelsteen, A.; Jansen, S; van Timmeren, A.; Roggema, R. Energy Potential Mapping A systematic approach to sustainable regional planning based on climate change, local potentials and exergy. In Proceedings of the CIB. World Building Congress 2007, CIB/CSIR, Cape Town, South Africa, 2007

2. Dobbelsteen, A. van den; Broersma, S.; Stremke, S.; Energy Potential Mapping for EnergyProducing Neighbourhoods. Int. J. Sustain. Build. Technol. Urban. Dev. 2011, 014, 170-176.

3. Broersma, S.; Fremouw, M.; van den Dobbelsteen, A 'Heat Mapping the Netherlands - Laying the foundations for energy-based planning'. In Proceedings SB11 Helsinki World Sustainable Building Conference (CD-Rom); Helsinki, Finland, 18-21 October 2011.

4. Cullen, J.; Allwood, J.M. Theoretical efficiency limits for energy conversion devices. Energy 2010, 35, 2059-2069.

5. MacKay, D. Sustainable Energy—Without the Hot Air, version 3.5.2; UIT: Cambridge, UK, 2008; pp. 203-213.

6. International Energy Agency. Energy Technology Perspectives; OECD/IEA, Paris, France, 2008; Volume 2, pp. 530-531.

7. Shukuya, M. Exergy concept and its application to the built environment. Building Environment 2009, 44, 1545-1550.

8. Müller-Kraenner, M. Energy Security; UNESCO Publishing/Earthscan: London, UK, 2008; pp. xi, 3-6, 11-12.

9. Intergovernmental Panel on Climate Change. Fourth Assessment Report: Climate Change 2007 (AR4), synthesis report, Topic 2: causes of change; Cambridge University Press, Cambridge, UK and New York, NY, USA, 2007; p. 2.

10. van den Dobbelsteen, A. Energy Potential Mapping. In The Architecture Annual 2006-2007; Bekkering, H., ten Doeschate, A., Hauptmann, D., den Heijer, A., Knaack, U., van Manen, S., Eds.; 010 Publishers: Rotterdam, Netherlands, 2008; pp. 76-81.

11. De Vaan, C. Wat is duurzaam wonen? Een onderlinge vergelijking tussen verschillende duurzaamheidsindicatoren. MSc thesis, Eindhoven University of Technology: Eindhoven, The Netherlands, 2007; p. 20.

12. Gommans, L. Gebiedsgerichte energetische systeemoptimalisatie, een onderzoek naar de mogelijkheden voor een duurzame regionale energietransitie. PhD Thesis, Delft University of Technology: Delft, The Netherlands, 2012.

13. Çomakl1, K.; Yüksel, B.; Çomakl1, Ö. Evaluation of energy and exergy losses in district heating network. J. Appl. Therm. Eng. 2004, 24, 1009-1017.

14. Stremke, S.; van den Dobbelsteen, A.; Koh, J. Exergy landscapes: exploration of second-law thinking towards sustainable landscape design. Int. J. Exergy 2011, 8, 148-174. 
15. Sciubba, E.; Wall, G. A brief commented history of exergy from the beginnings to 2004. Int. J. Thermodyn. 2007, 10, 1-26.

16. Valero, A.; Usón, S.; Torres, C. Application of thermoeconomics to industrial ecology. Entropy 2010, 12, 591-612.

17. Nakamura, S.; Kondo, Y. Waste Input-Output Analysis Concepts and Application to Industrial Ecology (Eco-Efficiency in Industry and Science); Springer: New York, NY, USA, 2009.

18. Voivontas, D.; Assimacopoulos, D.; Mourelatos, A. Evaluation of renewable energy potential using a GIS decision support system. Int. J. Renew. Energy 1998, 13, 333-344.

19. Ramachandraa, T.; Shruthi, B. Spatial mapping of renewable energy potential, Renew. Sustain. Energy Rev. 2007, 11, 1460-1480.

20. Broersma, S.; Fremouw, M.; van den Dobbelsteen, A. Warmtekaarten - Nederlandse warmtekarakteristieken in kaart gebracht (in Dutch). Delft University of Technology, Faculty of Architecture, 2010

21. Broersma, S.; Fremouw, M.; van den Dobbelsteen, A.; Stremke, S. Duurzame energiebeelden voor de Veenkoloniën (in Dutch); Delft University of Technology, Faculty of Architecture: Delft, The Netherlands, 2011.

22. Broersma, S.; van den Dobbelsteen, A.; van der Grinten, B.; Stremke, S. Energiepotenties Groningen - Energiepotentiestudie De Groene Compagnie (in Dutch); Delft University of Technology, Faculty of Architecture: Delft, The Netherlands, 2009.

(C) 2013 by the authors; licensee MDPI, Basel, Switzerland. This article is an open access article distributed under the terms and conditions of the Creative Commons Attribution license (http://creativecommons.org/licenses/by/3.0/). 